\title{
Controversial treatment of a victim of severe head injury complicated by septic shock and acute respiratory distress syndrome
}

This article was published in the following Dove Press journal:

International Medical Case Reports Journal

28 June 2011

Number of times this article has been viewed

\author{
Anniken Haavind' \\ Olav Hevrøy' \\ Rune Hennig', \\ Lars Bjertnaes ${ }^{1,3}$ \\ 'Division of Intensive Care Medicine, \\ Department of Anesthesiology; \\ ${ }^{2}$ Department of Neurosurgery, \\ University Hospital of North Norway; \\ ${ }^{3}$ Department of Clinical Medicine \\ (neurosurgery and anesthesiology), \\ Faculty of Health Sciences, University \\ of Troms $\varnothing$, Tromsø, Norway
}

\begin{abstract}
Pneumonia, severe sepsis, and acute respiratory distress syndrome (ARDS) are frequent complications after head trauma. Recombinant human activated protein C (APC) reportedly improves circulation and respiration in severe sepsis, but is contraindicated after head injury because of increased risk of intracranial bleeding. A 21-year-old man with severe head injury after a car accident was endotracheally intubated, mechanically ventilated, and hemodynamically stabilized before transfer to our university hospital. His condition became complicated with pneumonia, septic shock, ARDS, coagulation dysfunction, and renal failure. In spite of intensive therapy, oxygenation and arterial blood pressure fell to critically low values. Simultaneously, his intracranial pressure peaked and his pupils dilated, displaying no reflexes to light. His antibiotic regimen was changed and ventilation was altered to high frequency oscillations, and despite being ethically problematic, we added APC to his treatment. The patient recovered with modest neurological sequelae.
\end{abstract}

Keywords: activated protein C, acute respiratory distress syndrome, septic shock, severe head injury

\section{Introduction}

Victims of severe head trauma are prone to remote organ complications. ${ }^{1}$ Neurogenic pulmonary edema (NPE), pneumonia, sepsis, diabetes insipidus, coagulation dysfunction, acute respiratory distress syndrome (ARDS), and multiple organ dysfunctions syndrome (MODS) occur most frequently. ${ }^{1-4}$ Recombinant human activated protein $\mathrm{C}$ (APC), exerting anticoagulant, anti-inflammatory, anti-apoptotic, and profibrinolytic effects, reportedly improves cardiovascular and respiratory functions, and increases survival in severe sepsis. However, severe head injury within the last 3 months constitutes a contraindication against APC because of increased risk of intracranial bleeding. 5,6

The aim of this report was to describe the medical and ethical dilemmas when facing a young victim of severe head injury who was threatened by cerebral herniation as his condition became complicated with septic shock and ARDS, with lack of response to conventional therapy.

\section{Case report}

A 21-year-old man was found unconscious hanging in a head down position in his overthrown car, approximately $1 \frac{1}{2}$ hours after the accident. He was taken by ambulance to the local hospital where he arrived with a Glasgow Coma Scale score 
(GCS) of 4. Computed tomography on admission showed basilar skull fractures (Figure 1A), traumatic subarachnoid hemorrhage, scattered cerebral bleedings (Figure 1B), cerebral concussion, and brain edema (not shown in the figures). He was endotracheally intubated, mechanically ventilated, and hemodynamically stabilized with intravenous infusions of norepinephrine and dopamine (Table 1). The treatment continued uninterrupted during the transfer via air ambulance, staffed with an anesthesiologist and a nurse, to the intensive care unit (ICU) of our university hospital, where he arrived 7 hours after the accident. Here, his mean arterial pressure (MAP), intracranial pressure (ICP), cerebral
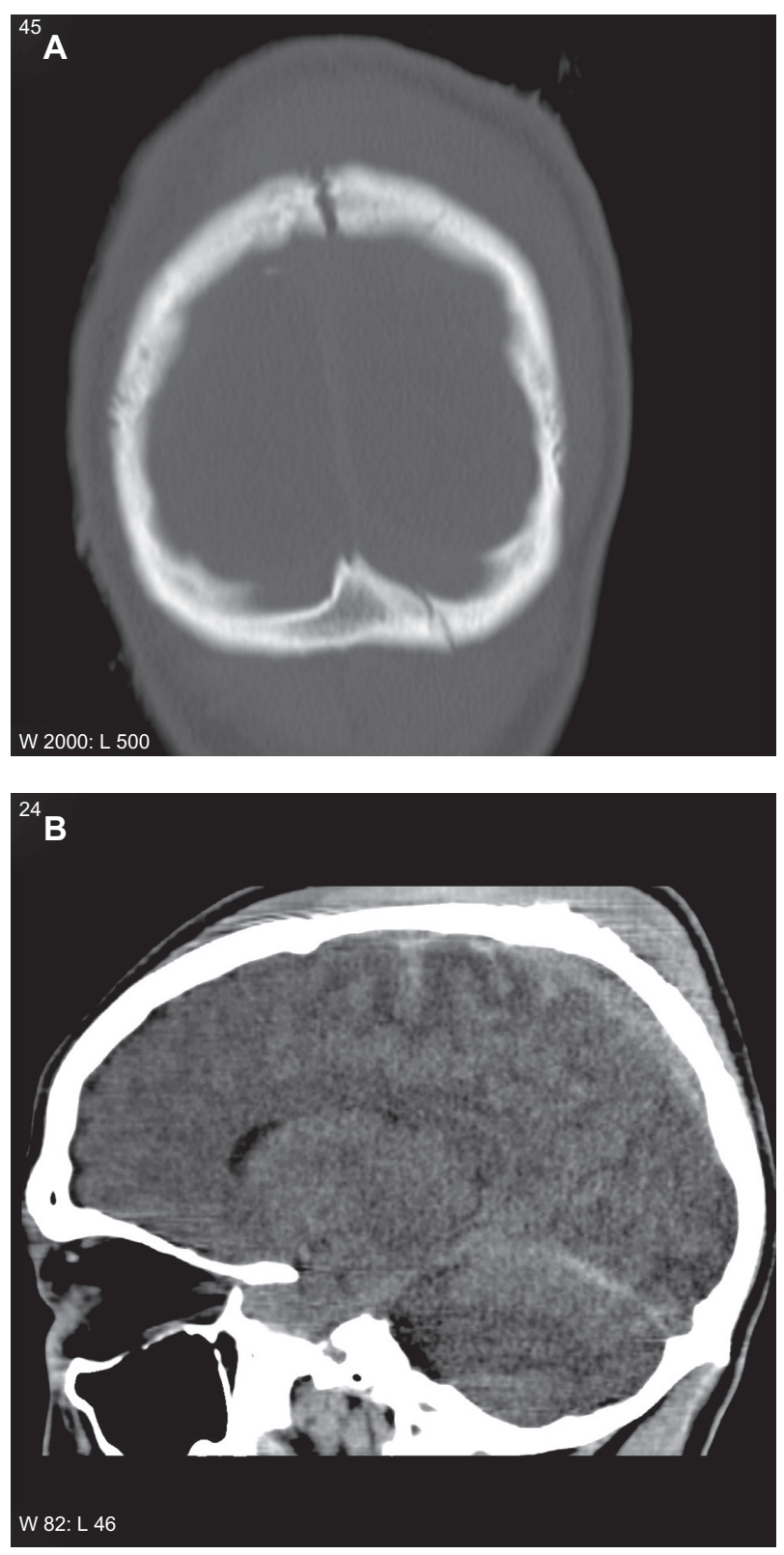

Figure I Head computed tomograms showing skull fractures (A) and scattered traumatic subarachnoid hemorrhages $(\mathbf{B})$. perfusion pressure $(\mathrm{CPP}=\mathrm{MAP}-\mathrm{ICP})$, and oxygenation ratio (arterial partial pressure of oxygen/fraction of inspired oxygen $\left[\mathrm{PaO}_{2} / \mathrm{FiO}_{2}\right]$ ), all presented as averages over 24 hours, initially displayed normal values (Table 1) and no indication for neurosurgical intervention was found.

On hospital day 3, ICP peaked above $30 \mathrm{mmHg}$ (not shown in Table 1) accompanied by pupillary dilation and diabetes insipidus that were treated with thiopental and desmopressin, respectively. Inflammation parameters increased and $\mathrm{PaO}_{2} / \mathrm{FiO}_{2}$ ratio decreased gradually. Despite the fact that he was prophylactically treated with cefotaxime because of his basilar skull fractures, he contracted bronchopneumonia. Since he required continuous hemodynamic support with moderate to high doses of norepinephrine and dopamine to maintain MAP above $70 \mathrm{mmHg}$ (Table 1), we suspected septicemia, and gentamycin, erythromycin, and hydrocortisone were added to the treatment.

On day 7 , his condition worsened with septic shock. Leukocytes and C-reactive protein (CRP) increased whereas $\mathrm{PaO}_{2} / \mathrm{FiO}_{2}$ ratio and thrombocytes fell (Table 1). Upon identification of Staphylococcus aureus in tracheal smears, cefotaxime was replaced by imepenem according to the resistance test. His chest X-ray (Figure 2) displayed opacities consistent with ARDS, and the following day extravascular lung water index (EVLWI; Table 1), as assessed by PiCCO (Pulsion Medical Systems, Munich, Germany), increased by almost three-fold. Simultaneously, diuresis declined from 200 to $20 \mathrm{~mL} /$ hour concomitant with a three-fold increase in serum creatinine. ICP peaked above $30 \mathrm{mmHg}$ a second time, and both pupils dilated maximally with no reactions to light. Veno-venous hemofiltration (Prismaflex ${ }^{\circledR}$ system, Gambro, Lund, Sweden) was started and continued over the subsequent 5 days. When $\mathrm{PaO}_{2} / \mathrm{FiO}_{2}$ ratio had fallen to a low point of $46 \mathrm{mmHg}$ (day 8), we replaced pressure-controlled mechanical ventilation (mean airway pressure of $26 \mathrm{~cm}$ $\mathrm{H}_{2} \mathrm{O}$, positive end-expiratory pressure [PEEP] of $8 \mathrm{~cm} \mathrm{H}_{2} \mathrm{O}$ and $\mathrm{FiO}_{2}$ of 1.0) with high frequency oscillatory ventilation (HFOV 3100B; VIASYS HealthCare, San Diego, CA) maintaining unchanged airway pressure and $\mathrm{FiO}_{2}$. In addition, he received an intravenous infusion of APC (drotrecogin-alpha, Xigris $^{\circledR}$, Eli Lilly and Co, Indianapolis, IN) $24 \mu \mathrm{g} / \mathrm{kg} /$ hour over 4 days. Twelve hours later, his MODS regressed; MAP and CPP increased from low points of 64 and $45 \mathrm{mmHg}$, respectively, and changes in EVLWI and markers of inflammation and coagulation regressed markedly. ICP decreased and hemodynamic support with norepinephrine and dopamine could be gradually withdrawn (Table 1). On day 12 , HFOV was replaced by conventional pressure-controlled 
Table I Physiological and pharmacological variables

\begin{tabular}{|c|c|c|c|c|c|c|c|c|c|c|c|c|c|c|c|}
\hline Day & $I$ & 2 & 3 & 4 & 5 & 6 & 7 & 8 & 9 & 10 & II & 12 & 13 & 14 & 15 \\
\hline NE (ng/kg/minute) & 65 & 72 & 90 & 0 & 50 & 145 & 250 & 480 & 600 & 480 & 150 & 60 & 0 & 0 & 0 \\
\hline DA $(\mu g / k g /$ minute $)$ & 10 & 10 & 20 & 10 & 10 & 0 & 10 & 13 & 13 & 10 & 6 & 0 & 0 & 0 & 0 \\
\hline MAP $(\mathrm{mmHg})$ & 72 & 72 & 87 & 91 & 79 & 78 & 75 & 64 & 80 & 76 & 87 & 86 & 81 & 81 & 84 \\
\hline $\mathrm{ICP}$ & 8 & 9 & 19 & 22 & 15 & 13 & 20 & 22 & 24 & 23 & 22 & 23 & 20 & 13 & 10 \\
\hline CPP & 65 & 65 & 70 & 62 & 65 & 65 & 51 & 45 & 54 & 62 & 65 & 57 & 60 & 67 & 65 \\
\hline $\mathrm{PaO}_{2} / \mathrm{FiO}_{2}(\mathrm{mmHg})$ & 379 & 332 & $13 \mid$ & $|4|$ & 123 & 191 & 50 & 46 & 59 & 103 & 195 & 206 & 218 & 210 & 208 \\
\hline SVRI $\left(\right.$ dyn $\left.\times \mathrm{s} / \mathrm{cm}^{5} / \mathrm{m}^{2}\right)$ & - & - & - & - & - & - & - & 560 & 910 & 1250 & 1290 & 1460 & 1560 & - & - \\
\hline $\mathrm{Cl}\left(\mathrm{L} / \mathrm{min} / \mathrm{m}^{2}\right)$ & - & - & - & - & - & - & - & 13.7 & 12.1 & 10.1 & 9.7 & 7 & 6 & - & - \\
\hline CRP (mmol/L) & 34 & 178 & 194 & 467 & 351 & 192 & 132 & 389 & 446 & 343 & 183 & 118 & 65 & 39 & 22 \\
\hline Leuko (10\%/L) & 14 & 13 & 13 & 12 & II & II & 18 & 25 & 30 & 28 & 22 & 14 & II & 9 & 8.3 \\
\hline $\operatorname{Trc}\left(10^{12} / \mathrm{L}\right)$ & 267 & 267 & 292 & 292 & 278 & 292 & 304 & 182 & 122 & 137 & 156 & 153 & 299 & 406 & 484 \\
\hline EVLWI (mL/kg) & - & - & - & - & - & - & - & 19 & 18 & 14.6 & II & 8 & 8 & - & - \\
\hline
\end{tabular}

Abbreviations: NE, norepinephrine; DA, dopamine; MAP, mean arterial pressure; ICP, average intracranial pressure; CPP, average cerebral perfusion pressure, all pressures presented as averages over 24 hours; $\mathrm{PaO}_{2}$, arterial partial pressure of oxygen; $\mathrm{FiO}_{2}$, fraction of inspired oxygen; SVRI, systemic vascular resistance index; $\mathrm{Cl}$, cardiac index; CRP, C-reactive protein; Leuko, leukocytes; Trc, thrombocytes; EVLWI, extravascular lung water index.

mechanical ventilation with PEEP $8 \mathrm{~cm} \mathrm{H}_{2} \mathrm{O}$. He was weaned off the respirator on day 17 and transferred to the Department of Rehabilitation, from whence he was discharged to his home after 2 months. Two years later, a right-sided paresis of the oculomotor nerve and a contralateral drop foot were his only sequelae.

Written informed consent was obtained from the patient for publication of this case report and the accompanying images. A copy of the consent is available for review by the Editor-in-Chief.

\section{Discussion}

It is difficult to predict the outcome of a patient with severe head injury who was hanging in a head down position for a lengthy period of time before rescue. Enhanced venous pressure transiently may have increased ICP and compromised his CPP at this early stage of injury. Despite the fact that his

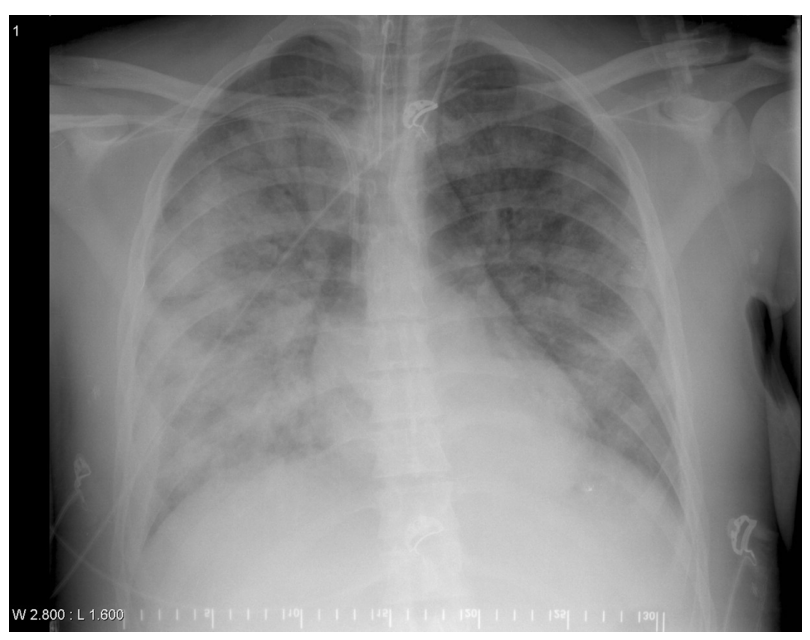

Figure 2 Chest $\mathrm{X}$-ray displaying opacities consistent with acute respiratory distress syndrome (ARDS). condition was complicated with pneumonia followed by severe sepsis and ARDS, he survived with modest sequelae after receiving intensive therapy including APC.

It is well documented that impaired cerebral blood flow after severe head injury leads to reduced brain tissue oxygen delivery and lactate accumulation. Reduction of cerebral blood flow, or decrease in oxygenation below a certain threshold value may escalate brain damage and eventually lead to cerebral herniation. ${ }^{7}$ According to a recent report, brain tissue oxygen tension $\left(\mathrm{PbtO}_{2}\right)$ after severe head injury can be improved by pharmacologically increasing CPP. ${ }^{8}$ Investigators also suggest that therapy based on continuous correction of $\mathrm{PbtO}_{2}$ is associated with reduced mortality and better short-term outcome. ${ }^{9}$ Concerning our patient, it is likely, albeit not proven, that septic shock and severe hypoxia combined might have prevented brain oxygenation from reaching the $\mathrm{PbtO}_{2}$ threshold despite receiving vasoconstrictor support at high rates (Table 1).

Victims of severe brain trauma have increased risk of developing coagulation disturbances, partly because the brain cortex is rich in tissue factor (TF). ${ }^{10}$ Abundantly released TF from the injured brain may induce coagulopathy reminding on disseminated intravascular coagulation. ${ }^{11}$ Independent risk factors for coagulopathy in isolated head injuries include GCS score $<8$, injury severity score $>16$, hypotension upon admission, cerebral edema, subarachnoid hemorrhage, and midline shift. ${ }^{11}$ Our patient met five of these criteria. Although his coagulation disturbances most likely resulted from severe sepsis, traumatic coagulopathy and brain hypoxia may have contributed to his illness.

In severe sepsis, bacterial products activate mediators that stimulate inflammation and coagulation. Transcription nuclear factor $\kappa \beta(\mathrm{NF}-\kappa \beta)$ and tumor necrosis factor $\alpha(\mathrm{TNF}-\alpha)$ are 
released from cells of the immune system and stimulate inducible nitric oxide synthase (iNOS) to excessive generation of NO in endothelial and vascular smooth muscle cells. NO contributes to circulatory shock and binds to superoxide anion to form peroxynitrite that causes derangements of endothelial and epithelial linings resulting in vascular leaks and decrease in pulmonary gas exchange typical of ARDS. ${ }^{12,13}$ Inhibitors of iNOS counteract septic shock, but do not increase survival from sepsis. ${ }^{14}$

Bacterial products also release TF from mononuclear cells which triggers the extrinsic pathway of the coagulation cascade when conjugated with activated factor VII ${ }^{15}$ Thus, it might be that brain trauma and bacterial products acted together to promote the coagulation disturbances in our patient.

Reportedly, $71 \%$ of the patients with head injury develop pneumonia. ${ }^{3}$ Aspiration pneumonia, NPE, and ventilatorassociated lung injury are difficult to distinguish from ARDS and possibly might have worsened his condition. ${ }^{1,4,13}$ However, since his chest X-rays showed no evidence of pulmonary edema upon arrival and the subsequent 2 days, we considered NPE to be a less likely explanation of his lung pathologies.

Application of positive pressure ventilation with PEEP might have contributed to the increase in ICP by impeding venous return. Even a relatively low PEEP of $6-8 \mathrm{~cm} \mathrm{H}_{2} \mathrm{O}$ might influence CPP negatively, but with decreasing effect as lung compliance decreases. ${ }^{14}$ However, when his oxygenation dropped to the lowest point, instead of increasing PEEP, we discussed the idea of treating him with extracorporeal membrane oxygenation which was discarded because it would require anticoagulant therapy with high doses of heparin. Therefore, we changed to high frequency oscillatory ventilation, although according to the literature, no increase in survival has been noticed in comparison with conventional mechanical ventilation. ${ }^{16,17}$

Since all conventional treatments had failed, the only possibility remaining was to perform a decompressive craniotomy, but the idea was abandoned because his condition indicated that he would probably not survive. His parents insisted that "something had to be done!", so we could see no option other than facilitating his general circulatory and respiratory conditions with the aim to improve his cerebral oxygenation.

The protein C Worldwide Evaluation in Severe Sepsis (PROWESS) trial had shown that treatment with APC resulted in a faster regression of circulatory and respiratory dysfunction, and increased survival in patients with severe sepsis. ${ }^{5,6}$ A retrospective study of patients with septic shock confirmed that APC rapidly improved vascular tone by decreasing the norepinephrine dose required to maintain arterial pressure. ${ }^{18}$ On the negative side, $0.47 \%$ of the patients randomized to receive APC had suspected intracranial hemorrhage during the infusion period. ${ }^{19}$ Correspondingly, a recent meta-analysis reported the rates of intracranial hemorrhage to around $0.4 \%$ and $0.7 \%$ during infusion and at 28 days, respectively. ${ }^{20}$ The abdominal surgery subgroup of patients in the PROWESS trial, complicating with severe sepsis, had a more than $9 \%$ reduction of the absolute risk of fatal outcome. The relative risk reduction for 28-day mortality in the abdominal surgery patients was $30 \%$ and in the high-risk patients, as defined by an Acute Physiology and Chronic Health Evaluation II score of 25 or greater, the relative risk reduction was $40 \%{ }^{21}$ Literature research revealed no controlled studies on the efficacy and safety of APC in septicemic patients with a primary head trauma. The only hit was the case report of an alcohol-intoxicated man, who arrived with subdural hematoma, with a GCS of 14. Although his trauma was milder compared with our patient, he became critically ill with sepsis and ARDS and survived with no rebleeding after treatment including APC. ${ }^{22}$

We decided to administer APC in spite of the ethical dilemma of prescribing a medicine which is formally contraindicated. ${ }^{5,6,20}$ On the other hand, the fact that severe sepsis with more than five organ dysfunctions has a mortality rate of $85 \%-90 \%$, presented a strong indication for APC. He undoubtedly would face cerebral herniation unless we managed to improve his cerebral oxygenation. ${ }^{23}$ We discussed the therapeutic alternatives and their potential complications openly with his parents, who gave their consent to start with APC.

Briefly, APC is an endogenously produced serine protease, catalyzed by thrombin/thrombomodulin complex when protein $\mathrm{C}$ is bound to its endothelial receptor. It acts by proteolytic cleavage of activated coagulation factors $\mathrm{V}$ and VIII and escalates fibrinolysis by inhibiting plasminogen activator inhibitor- $1 .{ }^{24} \mathrm{APC}$ attenuates inflammation by inhibiting the translocation of NF- $\kappa \beta$, suppressing the release of proinflammatory cytokines and adhesion molecules, and reducing the accumulation of leukocytes in the alveoli. ${ }^{25-27}$ Cleavage of the protease-activated receptor-1 by the APCendothelial cell receptor complex exerts anti-apoptotic and enhanced barrier-protective effects in endothelial cells. ${ }^{28,29}$ In rats subjected to infusion of endotoxin, APC inhibits the induction of iNOS by decreasing TNF- $\alpha$ production, thereby preventing circulatory shock. ${ }^{30}$

We speculated whether APC might counteract coagulopathy after general trauma and after severe head injury 
in particular. ${ }^{10,11}$ A prospective study of major trauma patients revealed that those with low tissue perfusion upon arrival, as indicated by a high base deficit, high thrombomodulin, and low plasma protein C levels, had increased mortality. ${ }^{31}$ We found, however, no clinical investigation specifically focusing on the effect of APC on coagulopathy after isolated head trauma. We assume that our patient, at least transiently, suffered from low tissue perfusion, but thrombomodulin and protein $\mathrm{C}$ levels were not determined.

As of today, information is sparse as to whether APC could be of potential benefit after traumatic brain injury. Investigators recently noticed that after standardized cortical trauma in mice, APC reduced the volume of lesions and improved the neurological outcome. They also compared wild-type APC with an APC analog with reduced anticoagulant and normal cytoprotective activity for late treatment. The APC analog displayed greater neuroprotective effect and less intracranial bleeding compared with wild-type APC. ${ }^{32,33}$

Whether APC, which was primarily administered against septic shock, also acted beneficially on brain injury per se, remains elusive. Since his condition improved with a decrease in ICP, we believe that APC through its improvement of circulation and respiration might have contributed to his recovery that left him with modest sequelae only. However, his recovery inspires us to suggest a future controlled randomized trial of the efficacy and safety of an APC analog with reduced anticoagulant and maintained cytoprotective activity, if it will be available, in patients with MODS after severe head injury.

\section{Conclusion}

Although ethically controversial because of increased risk of intracranial bleeding, APC should not be rejected as part of a rescue therapy in cases of severe head injury complicating with septic shock and ARDS not responding to conventional therapy. However, as a general rule, decisions to treat should be taken based on evidence from controlled randomized trials and not from animal experiments or case reports.

\section{Disclosure}

The authors declare that they have no competing interests in this work.

\section{References}

1. Piek J, Chesnut RM, Marshall LF, et al. Extracranial complications of severe head injury. J Neurosurg. 1992;77:901-907.

2. Rogers FB, Shackford SR, Trevisani GT, Davis JW, Mackersie RC, Hoyt DB. Neurogenic pulmonary edema in fatal and nonfatal head injuries. J Trauma. 1995;39:860-866.
3. Eckert MJ, Davis KA, Reed RL 2nd, et al. Urgent airways after trauma: who gets pneumonia? J Trauma. 2004;57:750-755.

4. Holland MC, Mackersie RC, Morabito D, et al. The development of acute lung injury is associated with worse neurologic outcome in patients with severe traumatic brain injury. J Trauma. 2003;55:106-111.

5. Bernard GR, Vincent JL, Laterre PF, et al. Efficacy and safety of recombinant human activated protein $\mathrm{C}$ for severe sepsis. Recombinant human protein C Worldwide Evaluation in Severe Sepsis (PROWESS) study group. $N$ Engl J Med. 2001;344:699-709.

6. Vincent JL, Angus DC, Artigas A, et al; Recombinant Human Activated Protein C Worldwide Evaluation in Severe Sepsis (PROWESS) Study Group. Effects of drotrecogin alfa (activated) on organ dysfunction in the PROWESS trial. Crit Care Med. 2003;31:834-840.

7. Ghajar J. Traumatic brain injury. Lancet. 2000;356:923-929.

8. Johnston AJ, Steiner LA, Coles JP, et al. Effect of cerebral perfusion pressure augmentation on regional oxygenation and metabolism after head injury. Crit Care Med. 2005;33:189-195.

9. Maloney-Wilensky E, Gracias V, et al. Brain tissue oxygen and outcome after severe traumatic brain injury: a systematic review. Crit Care Med. 2009;37:2057-2063.

10. Halpern CH, Reilly PM, Turtz AR, Stein SC. Traumatic coagulopathy: the effect of brain injury. J Neurotrauma. 2008;25:997-1001.

11. Talving P, Benfield R, Hadjizacharia P, Inaba K, Chan LS, Demetriades D. Coagulopathy in severe traumatic brain injury: a prospective study. J Trauma. 2009;66:55-61.

12. Beckman JS, Koppenol WH. Nitric oxide, superoxide, and peroxynitrite: the good, the bad, and ugly. Am J Physiol. 1996;271:C1424-C1437.

13. Bernard GR, Artigas A, Brigham KL, et al. The American-European Consensus Conference on ARDS. Definitions, mechanisms, relevant outcomes, and clinical trial coordination. Am J Respir Crit Care Med. 1994;149:818-824.

14. Watson D, Grover R, Anzueto A, et al; Glaxo Wellcome International Septic Shock Study Group. Cardiovascular effects of the nitric oxide synthase inhibitor NG-methyl-L-arginine hydrochloride (546C 88 ) in patients with septic shock: results of a randomized, double-blind, placebo-controlled multicenter study (study no. 144-002). Crit Care Med. 2004;32:13-20.

15. Gando S, Nanzaki S, Morimoto Y, Kobayashi S, Kemmotsu O. Systemic activation of tissue-factor dependent coagulation pathway in evolving acute respiratory distress syndrome in patients with trauma and sepsis. J Trauma. 1999;47:719-723.

16. Caricato A, Conti G, Della Corte F, et al. Effects of PEEP on the intracranial system of patients with head injury and subarachnoid hemorrhage: the role of respiratory system compliance. $J$ Trauma. 2005;58:571-576.

17. Derdak S, Mehta S, Stewart TE, et al. High-frequency oscillatory ventilation for acute respiratory distress syndrome in adults: a randomized, controlled trial. Am J Respir Crit Care Med. 2002;166:801-808.

18. Monnet X, Lamia B, Anguel N, Richard C, Bonmarchand G, Teboul JL. Rapid and beneficial hemodynamic effects of activated protein $\mathrm{C}$ in septic shock patients. Intensive Care Med. 2005;31:1573-1576.

19. Ely EW, Bernard GR, Vincent JL. Activated protein C for severe sepsis. N Engl J Med. 2002;347:1035-1036.

20. Khan A, Agarwal R, Aggarwal AN, Gupta D. Prevalence of serious bleeding events and intracranial hemorrhage in patients receiving activated protein C: a systematic review and meta-analysis. Respir Care. 2010;55:901-910.

21. Barie PS, Williams MD, McCollam JS, et al. PROWESS Surgical Evaluation Committee. Benefit/risk profile of drotrecogin alfa (activated) in surgical patients with severe sepsis. Am J Surg. 2004;188:212-220.

22. Schuster R, Waxman K. Successful Treatment of severe sepsis with recombinant human activated protein $\mathrm{C}$ in a patient with traumatic intracranial hemorrhage. J Trauma. 2007;63:E34-E36.

23. Brun-Buisson C, Doyon F, Carlet J, et al. Incidence, risk factors, and outcome of severe sepsis and septic shock in adults. A multicenter prospective study in intensive care units. French ICU Group for Severe Sepsis. JAMA. 1995;274:968-974. 
24. Esmon CT. The protein C pathway. Chest. 2003;124:26S-32S.

25. Joyce DE, Nelson DR, Grinnell BW. Leukocyte and endothelial cell interactions in sepsis: relevance of the protein $\mathrm{C}$ pathway. Crit Care Med. 2004;32:S280-S286.

26. Yuksel M, Okajima K, Uchiba M, Horiuchi S, Okabe H. Activated protein $\mathrm{C}$ inhibits lipopolysaccharide-induced tumor necrosis factor-alpha production by inhibiting activation of both nuclear factorkappa B and activator protein-1 in human monocytes. Thromb Haemost. 2002;88:267-273.

27. Nick JA, Coldren CD, Geraci MW, et al. Recombinant human activated protein $\mathrm{C}$ reduces human endotoxin-induced pulmonary inflammation via inhibition of neutrophil chemotaxis. Blood. 2004;104:3878-3885.

28. Feistritzer C, Riewald M. Endothelial barrier protection by activated protein $\mathrm{C}$ through PAR1-dependent sphingosine 1-phosphate receptor-1 crossactivation. Blood. 2005;105:3178-3184.

29. Finigan JH, Dudek SM, Singleton PA, et al. Activated protein C mediates novel lung endothelial barrier enhancement: role of sphingosine 1-phosphate receptor transactivation. J Biol Chem. 2005; 280:17286-17293.
30. Isobe $\mathrm{H}$, Okajima $\mathrm{K}$, Uchiba $\mathrm{M}$, et al. Activated protein $\mathrm{C}$ prevents endotoxin-induced hypotension in rats by inhibiting excessive production of nitric oxide. Circulation. 2001;104:1171-1175.

31. Brohi K, Cohen MJ, Ganter MT, Matthay MA, Mackersie RC, Pittet JF. Acute traumatic coagulopathy: initiated by hypoperfusion: modulated through the protein C pathway? Ann Surg. 2007;245:812-818.

32. Petraglia AL, Marky AH, Walker C, Thiyagarajan M, Zlokovic BV. Activated protein $\mathrm{C}$ is neuroprotective and mediates new blood vessel formation and neurogenesis after controlled cortical impact. Neurosurgery. 2010;66:165-171.

33. Walker CT, Marky AH, Petraglia AL, Ali T, Chow N, Zlokovic BV. Activated protein $\mathrm{C}$ analog with reduced anticoagulant activity improves functional recovery and reduces bleeding risk following controlled cortical impact. Brain Res. 2010;1347:125-131.

\section{Publish your work in this journal}

The International Medical Case Reports Journal is an international, peer-reviewed open-access journal publishing original case reports from all medical specialties. Previously unpublished medical posters are also accepted relating to any area of clinical or preclinical science. Submissions should not normally exceed 2,000 words or
4 published pages including figures, diagrams and references. The manuscript management system is completely online and includes a very quick and fair peer-review system, which is all easy to use. Visit http://www.dovepress.com/testimonials.php to read real quotes from published authors.

\footnotetext{
Submit your manuscript here: http://www.dovepress.com/international-medical-case-reports-journal-journal
} 